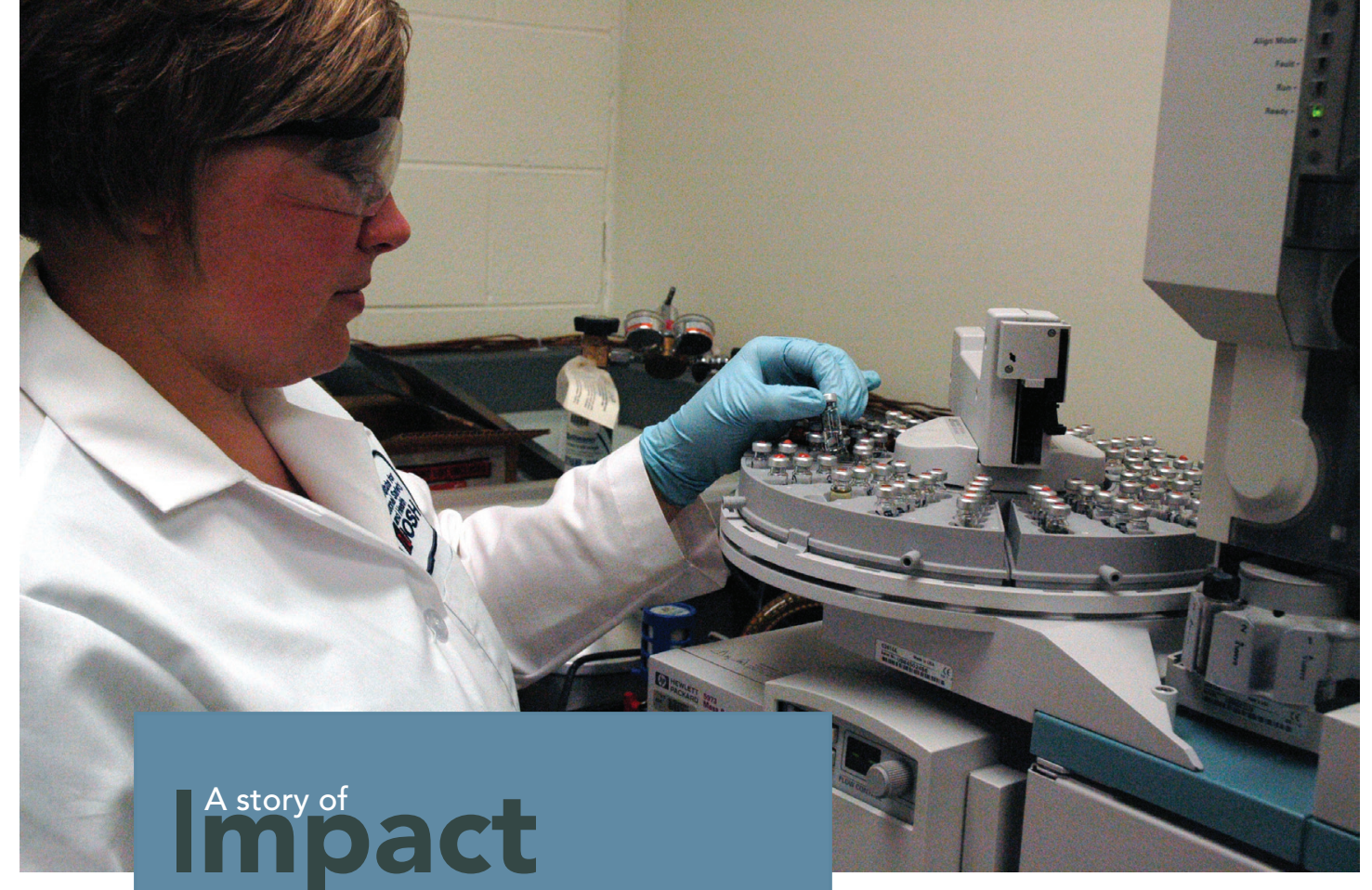

NIOSH Manual of Analytical Methods Provides Analytical Tools that Help Keep Workers Safe

Many goods essential to daily life are produced using hazardous chemicals. One result is that workers may be exposed to hazardous chemicals at their job. Monitoring these exposures can determine if action is needed to reduce or eliminate exposure. The $\mathrm{Na}$ tional Institute for Occupational Safety and Health (NIOSH) has developed and rigorously evaluated over 300 methods that are available in the NIOSH Manual of Analytical Methods (NMAM). These methods describe how to collect samples and analyze them against known standards. The results can indicate whether action is needed to reduce exposure.

One example of how methods can help solve workplace problems involved workers at a printing company who experienced blurry vision. NIOSH scientists talked to workers about their symptoms, and reviewed plant operations as well as the chemicals being used. After identifying the compounds most likely to cause the blurry vision, air samples were collected and analyzed using a NIOSH method. These data helped confirm that workers' symptoms correlated to exposure to a specific compound,
- A NIOSH researcher analyzing samples to measure the chemical that causes blurry vision.

\section{Relevant Information}

An industry information sheet for workers was revised to warn about blurry vision caused by using this compound, dimethylisopropanolamine.

EPA included the findings in a report for the print industry outlining the issue and the solution.

\section{Exposures can be reduced to the 38,000} workers in the flexographic print industry by implementing changes learned from these visits. ${ }^{[1,2,3]}$

In 2010, 725,000 visits were made to the NMAM webpages. ${ }^{[4]}$

\section{f $[B$}

Follow NIOSH on Facebook and Twitter Sign up for eNews at cdc.gov/niosh/enews 
dimethylisopropanolamine. NIOSH advised the company about steps they could take to eliminate the problem. After these changes were made, NIOSH returned a year later to confirm that workers' vision had returned to normal and that the plant air concentration was lower for that compound. ${ }^{[2,3]}$ This is just one example of how the $300+$ methods in NMAM can help keep workers safe.

\section{Impact}

The occupational safety and health (OSH) community worldwide, other countries' OSH agencies, and commercial laboratories turn to NIOSH for assistance in developing new methods, for finding solutions to monitoring occupational exposures, and for resolving analytical problems related to worker health and safety. In addition, commercial products to detect lead, beryllium, and methamphetamine have been developed that are based on NIOSH methods. These kits: Full Disclosure ${ }^{\circledR}$, BeFinder ${ }^{\oplus}$, MethAlert ${ }^{\circledR}$ and MethChek $^{\circledR}$, can be used on site providing a rapid indication of contamination..$^{[5,6,7]}$ Once the degree of contamination is known, users can then select personal protective equipment (goggles, gloves, impervious clothing, or respirators for example) or take other actions to avoid exposure to these hazards.

NIOSH works with professional organizations and regulatory agencies to provide both consultation and rigorous research that is responsive to current occupational health issues. Recognized as a leading source for reliable, accurate analytical methods, NMAM is one of the most frequently consulted and requested documents from the NIOSH Web site. These methods are accessible to people worldwide from the U.S. Government Printing Office, are located in the NIOSH Pocket Guide (http://www.cdc.gov/niosh/npg/) and on the NIOSH Web, http://www.cdc.gov/niosh/nmam/ (or call 1.800.232.4636 for more information).

[1] Bureau of Labor Statistics [2008]. BLS Quarterly Census of Employment and Wages. http://www.bls.gov/oco/ $\mathrm{cg} / \mathrm{cgs} 050 . \mathrm{htm}$.

[2] NIOSH [2002]. Health Hazard evaluation report: HETA \#2002-0379-2901, Superior Label Systems, Mason, Ohio. http://www.cdc.gov/niosh/hhe/reports/pdfs/2002-0379-2901.pdf. National Institute for Occupational Safety and Health, Centers for Disease Control and Prevention, Department of Health and Human Services.

[3] Page EH, Cook CK, Hater MA, Mueller CA, Grote AA, Mortimer VD [2003]. Visual and ocular changes associated with exposure to two tertiary amines. J Occup Environ Med. 2003;60:69-75 doi:10.1136/oem.60.1.69

[4] Statistic based on Omniture SiteCatalyst software data retrieved on 22 April 2011. This software is used to track traffic on the NIOSH webpages.

[5] Full Disclosure. http://www.skcinc.com/prod/550-001.asp

[6] Beryllium detection kit. http://berylliant.net/products.html

[7] SKC Inc., MethAlert kit. http://www.skcinc.com/prod/560-001.asp. MethChek kit. http://www.skcinc.com/ prod/560-002.asp. Accessed June 16, 2011.

Disclaimer: Mention of company names or products does not constitute endorsement by the Centers for Disease Control and Prevention.

\section{SAFER • HEALTHIER • PEOPLE ${ }^{T M}$}

U.S. Department of Health and Human Services

Centers for Disease Control and Prevention

National Institute for Occupational Safety and Health

To receive NIOSH documents or more information about occupational safety and health topics, please contact NIOSH. Telephone: 1-800-cdc-info (1-800-232-4636) | TTY: 1-888-232-6348 | email: cdcinfo@cdc.gov | www.cdc.gov/niosh For a monthly update on news at NIOSH, subscribe to NIOSH eNews by visiting www.cdc.gov/niosh/eNews. DHHS (NIOSH) Publication No. 2012-113
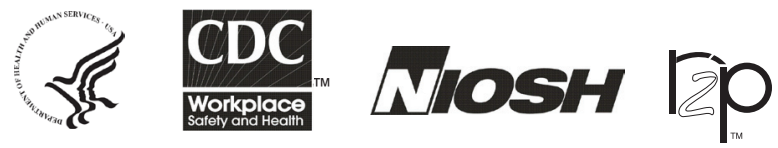